\title{
Protection of the environment in the 21st century: radiation protection of the biosphere including humankind
}

\section{Statement of the International Union of Radioecology (IUR)}

\author{
F. Bréchignac ${ }^{1}$, G. Polikarpov ${ }^{2, *}$, D. H. Oughton $^{3}$, G. Hunter ${ }^{4}$, R. Alexakhin ${ }^{5}$, Y. G. Zhu ${ }^{6}$, J. Hilton ${ }^{7}$, P. Strand ${ }^{8}$ \\ ${ }^{1}$ Institute for Radioprotection and Nuclear Safety, Centre of Cadarache, France \\ ${ }^{2}$ Kovalevsky Institute of Biology of the Southern Seas, Sevastopol, Ukraine \\ ${ }^{3}$ Agricultural University of Norway, Ås, Norway \\ ${ }^{4}$ Scottish Environment Protection Agency, Stirling, United Kingdom \\ ${ }^{5}$ Russian Institute of Agricultural Radiology and Agroecology, Obninsk, Russia \\ ${ }^{6}$ Research Centre for Eco-environ. Sciences, Chinese Academy of Sciences, Beijing, China \\ ${ }^{7}$ Center for Ecology and Hydrology, Winfrith Technology Centre, Dorset, United Kingdom \\ ${ }^{8}$ Norwegian Radiation Protection Authority, Østeras, Norway
}

\begin{abstract}
In order to draw the attention of EEIU and IUR members, as well as others interested in the ecological/environmental aspects of radioactivity as related to ethics, science and politics, ESEP presents the key IUR Statement Protection of the environment in the 21st century: radiation protection of the biosphere including humankind (Brechignac et al. 2003), which is currently in press with the Journal of Environmental Radioactivity. More information about the IUR is available at www.iur-uir.org.
\end{abstract}

KEY WORDS: IUR - Statement - Ecocentric $\cdot$ Biosphere $\cdot$ Radiation · Environment

Resale or republication not permitted without written consent of the publisher

\section{INTRODUCTION}

The issue of protection of the environment is now more and more debated in connection to human health. This is prompting significant evolutions in the field of radioprotection. After prior and successful emphasis placed directly on human health, radioprotection currently enlarges its scope and concerns to consider also the fauna, flora and abiotic compartments of the environment, recognising that human health requires a healthy environment. Radioecology, which addresses the environmental impact of radioactivity, both plays a central role and holds a particular responsibility in this context. Given the proliferating initiatives which are currently growing worldwide, from science to ethics, philosophy, legal and regulatory aspects, and the variety of potential approaches and views which they generate, the International Union of
Radioecology has built a consensual statement in order to define its position and future directions of work. In brief, the IUR recommends that further development of the scientific basis for protection of the environment from radiation is to be undertaken to fill some crucial knowledge gaps. Whilst ensuring their future credibility, this should be carried out in parallel with current activities aimed at producing interim practical regulatory frameworks.

\section{THE CHALLENGE}

The start of the 21st Century is marked by a growing societal concern over human-driven impacts on the environment. This concern is exacerbated by both global environmental problems and a growing awareness that human health is strongly influenced by the quality, or healthiness, of the environment. Radioecology, which addresses the impacts of environmental radioactivity, is therefore called on to enlarge its focus from a prior emphasis on the goal to protect humans, to the protection of the environment as a whole, including humans. This evolution requires a reappraisal of the link between human health and environmental protection in general. Furthermore, the development of ecologically acceptable and justified use of nuclear power and radioactive materials (including issues such as waste disposal and enhanced natural radiation) require robust and transparent understanding of the radioecological consequences as well as consideration and accurate evaluation of the risks associated with potential accidents. 


\section{HISTORICAL CONTEXT}

The IUR was established in 1970 as an international scientific organisation to develop, inform and advise on all aspects related to radioactivity in the environment. While other international bodies were developing general principles of environment protection that were being consolidated in various regulatory frameworks (UN conventions, EU Directives, etc.), the IUR pioneered, in 1997, the first attempts to incorporate these into a framework for environmental radioprotection. These ideas were presented to the wider radiological protection community in 2000, and especially at the IRPA-10 symposium (Strand et al. 2000). Next in 2001, the IUR jointly arranged a consensus conference (IUR 2001) to discuss ethical, philosophical and environmental issues related to this theme. The Union has consequently been closely associated with further developments undertaken under the auspices of various international organisations (IAEA, UNSCEAR, NEA/OECD, ICRP, $\mathrm{EC}, \mathrm{WHO}, \mathrm{FAO}$, and national institutions) which, today, tackle various facets of the problem - safety standards, international guidance, consensus on ethical and legal aspects, framework for future regulations, assessment of the existing scientific knowledge and international trading. A document presenting IUR's standpoint on protection of the environment from ionising radiation which underpins scientific but also ethical, legal and social aspects of the subject, was published in 2002 (IUR 2002). Being the only organisation that is fully centred on, and dedicated to, radioactivity in the environment, the IUR holds, in this context, a particular responsibility. Due to its historic origins and constitution, the IUR is well suited to provide guidance on the coordination of international efforts in a balanced, cooperative and complementary manner.

\section{SCIENTIFIC BASIS FOR ENVIRONMENT RADIOPROTECTION}

The extensive effort devoted to the protection of humans from radiation has resulted in considerable advances in radiobiological and toxicological understanding of the interaction of radioactivity with life. Since the beginning of radioecology, a large amount of scientific information has accrued on the behaviour and impacts of radionuclides in the environment. The historic focus on anthropocentric problems such as contamination of food-stuffs resulted in a strong emphasis on transfer of radionuclides through food chains. Widening the scope of radioecology to consider also the radiation protection of non-human biota requires a transition to a truly ecocentric approach in order to address the composite effects of ionising radiation on man, biota and the ecosystems that they inhabit. Currently, those effects are much better known in situations of acute exposure to high doses of radiation upon individuals. However, a strong consensus exists that to address protection of the environment it is necessary to consider impacts on populations/ecosystems of low doses of radiation in chronic exposure to multi-pollutant mixtures. Whilst this requires assimilation of knowledge from numerous disciplines ranging from environmental toxicology to ecology, it also requires action to fill the specific knowledge gaps listed below.

\section{GAPS IN SCIENTIFIC KNOWLEDGE AND DEVELOPMENT REQUIRING CONSIDERATION}

- Knowledge on the transfer, bioaccumulation and metabolism of both naturally occurring and anthropogenic radionuclides in a variety of ecosystems (specifically non-human food-chains) and a better understanding of the processes and mechanisms that influence transfer and bioavailability.

- Understanding the effects of low doses of radiation to biota in chronic exposure, over several generations, with further emphasis on bioaccumulation. Development of a general conceptual model describing the effects of long-term exposures to ionising radiation (including $\alpha$ and $\beta$ emitters) at all existing and possible dose rates upon all life's organisation levels, based on the study of the most radiosensitive structures and functions. Clarification of the significance of the lowdose driven cytogenetic and by-stander effects currently observed.

- Identification of a variety of pertinent endpoints/criteria (effects), at individual and community/ecosystem levels, to allow for rating comparisons in impact assessments, and the development of suitable biomarkers and biomonitors correlated to those endpoints.

- Consideration of effects resulting from multi-pollutant mixtures containing radioactive and non-radioactive pollutants.

- Coping with extrapolation problems across levels of biological organisation (from molecular through individuals to ecosystems).

- Comparative analysis of simultaneous radiation protection aspects of both, humans and biota as components of single ecosystems in particular situations. Harmonization of the future system of radioprotection and the system of protection against chemical toxicants (compatibility with Ecological Risk Assessment approach).

- Development of Quantities and Units relating the detriment to biota and the biosphere resulting from radiation and chemical pollutants, and permitting comparison of their relative and synergistic effects. 


\section{PRINCIPLES OF RADIATION PROTECTION OF THE ENVIRONMENT}

Whilst acknowledging the advances achieved through the strict anthropocentric approach that previously dominated radiation protection, the IUR supports a transition to a globally ecocentric approach that aims to preserve the integrity of ecosystems due to both their inherent value as well as their essential supplies to humankind such as life support and various services. This could be summarized by 'human health requires a healthy environment'. Principles of radiation protection of the environment need to address various aspects of ecological risk assessment and management (sustainable development, conservation, biodiversity maintenance, responsibility, human dignity) as well as practical solutions directed at reducing these risks (precautionary approach, prevention, best available technology, substitution, polluters-pay, stakeholder participation, environmental impact assessment).

\section{MANAGEMENT AND RECOMMENDATIONS}

To date, the development of a radioprotection system of the environment has focused on a dosimetric assessment of radiation effects on 'reference' individual organisms through a set of 'umbrella endpoints' (mortality, morbidity, reproductive success, scorable cytogenetic effects). While this preliminary approach is a necessary component of any environmental impact assessment, and forms a fundamental evaluation scaled to the current scientific knowledge, it is not sufficient to address the complexity of the problem. The IUR stresses that quite significant gaps still lie between the ultimate goal of protection (individuals, populations and ecosystems exposed to chronic and low doses of mixed pollutants) and the currently feasible practical approach to achieve it. The IUR therefore recommends that further development of the scientific basis for protection of the environment from radiation, addressing the issues outlined above, be carried out in parallel with current activities aimed at producing interim practical regulatory frameworks. By such means, both these goals may be secured with objective and scientifically sound justification and synergy.

\section{PERSPECTIVES AND GOALS FOR IUR}

In this context, the goals that are to be pursued by the IUR through forthcoming actions revolve around several issues identified above. It is of primary importance to recall that the Union's main role is based on science, promoting its advancement, the dissemination of its knowledge and the communication of this to society. As such, the IUR does not set out to promote particular standards and/or regulations, but to contribute to the international effort aimed at developing a general framework that will allow such management tools to be derived from a sound scientific basis. A further strength brought by the IUR is the capacity of the multidisciplinary scientific community gathered within the Union to provide expert, informed, up-to-date and independent scientific advice, incorporating the knowledge from wider environmental fields not focused uniquely on radioactivity. Finally, the ultimate goal of the IUR is to ensure that the radioprotection of both man and the environment are considered with a scientifically sound, balanced, appropriately precautionary approach that permits sustainable development and technical innovation.

\section{F. Bréchignac, G. Polikarpov, D.H. Oughton, G. Hunter, R. Alexakhin, Y.G. Zhu, J. Hilton, and P. Strand}

\section{IUR Executive Board}

IUR Secretariat: IRSN-DPRE/SERLAB Centre d'Etudes de Cadarache, BP 3 13115, St-Paul-lez-Durance, France (www.iur-uir.org)

Acknowledgements. The authors of this statement are forming the current elected Board of Council of the IUR. Whilst expressing this consensual viewpoint in their respective names, they have drawn this position by synthesizing the many discussions and brain stormings held with the members at large, and particularly those actively contributing to the IUR Task Groups (IUR 2000, 2001, 2002). This statement could not have been achieved without their continuous and dedicated involvement.

\section{LITERATURE CITED}

Bréchignac F, Polikarpov G, Oughton DH, Hunter G, Alexakhin R, Zhu YG, Hilton J, Strand P (2003) Protection of the environment in the 21st century: radiation protection of the biosphere including humankind. Statement of the International Union of Radioecology. J Environ Radioactivity (in press)

IUR (2000) Dose and effects to non-human systems. Summary of the work of the action group of IUR. IUR Report 01, Oslo, Norway, available at http://www.iur-uir.org

IUR (2001) Consensus conference statement on protection of the environment. Oslo, Norway, available at http:// www.iur-uir.org

IUR (2002) Protection of the environment. Current status and future work. IUR Report 03, Oslo, Norway, available at http://www.iur-uir.org

Strand P, Brown JE, Woodhead DS, Larsson C-M (2000) Delivering a system and the framework for the protection of the environment from ionising radiation. In: Proceedings of IRPA 10, Hiroshima, Japan 